\title{
Retrospective study of multiple factors imparting effect on pregnancy outcomes in an in-vitro-fertilization centre
}

\author{
Preksha T. Singh*, Shreyans D. Singhvi, Utkarsh Kachhia, Trishala Punjabi, Shital Punjabi, \\ Rajesh Punjabi
}

Department of Obstetrics and Gynecology, Shashwat IVF, Ahmedabad, Gujarat, India

Received: 01 April 2020

Accepted: 29 April 2020

\section{*Correspondence:}

Dr. Preksha T. Singh,

E-mail: prekshasingh@icloud.com

Copyright: (C) the author(s), publisher and licensee Medip Academy. This is an open-access article distributed under the terms of the Creative Commons Attribution Non-Commercial License, which permits unrestricted non-commercial use, distribution, and reproduction in any medium, provided the original work is properly cited.

\begin{abstract}
Background: Assisted reproductive technology (ART) cycles include in vitro fertilization of the sperm and ovum and transferring the embryo formed into the uterus of the patients. In ART cycles, there is still a shroud of doubt regarding the pregnancy outcomes of embryo transfer on day 3 versus the embryo transfers on day 5 as well the better pregnancy outcome with fresh versus frozen embryo transfer and the number of embryos transferred. This study is aimed to evaluate these factors and study the way to optimize methods to obtain highest pregnancy outcomes.

Methods: A retrospective study was performed of 87 patients who had undergone embryo transfers during the duration of the study from an IVF centre in Ahmedabad. Multiple factors were studied and the clinical outcome was tabulated. The pregnancy outcomes were compared using the values of beta- hcg (human chorionic gonadotropin). The data was compiled and analyzed using Google spreadsheets. To find the statistical difference between different factors- the statistical method of Fischer's exact test and p-value was used.

Results: No statistical difference between day 3 and day 5 embryo transfer as well as between frozen and fresh embryo transfer were both. All of them were found equally efficacious, although 3 and 5 number of embryo transfers were found efficacious.

Conclusions: In conclusion authors recommend a day 5 embryo transfer with 3 or 5 embryos which are best-quality frozen or fresh embryos to achieve maximum pregnancy outcomes.
\end{abstract}

Keywords: Embryo, In-vitro-fertilization, Pregnancy

\section{INTRODUCTION}

Assisted reproductive technology (ART) cycles include in vitro fertilization of the sperm and ovum and transferring the embryo formed into the uterus of the patients. It's recently been used profoundly and it is extremely helpful for patients experiencing infertility. There are multiple number of IVF centres in India which are successfully working. The effectiveness of the ART cycles depends on three main parameters: embryo quality, endometrial receptivity (ER), and a wellbalanced embryo- endometrium interaction. ${ }^{1}$ In ART cycles, there is still a shroud of doubt regarding the pregnancy outcomes of embryo transfer on day 3 versus the embryo transfers on day 5 (blastocyst stage). Embryo transfer can take place on embryo development day 2 (four cell stage), 3 (eight cell stage), or 5 (blastocyst stage). It is usually found that the outcomes tend to improve, the longer the transfer is delayed, because of the benefits of improved qualitative embryo selection. ${ }^{2}$ Day 3 transfers are preferred sometimes if there is a question regarding the survival of embryos till day 5. In the past, day 5 transfers weren't successful because of poor quality of culture medium. However, now the scenario has changed and some studies show an equal efficiency of day 3 and day 5 transfer while some show that day 5 are superior. So, through this study, the aim is to determine if there is any difference between the two and what would 
give the best result in Indian patients with the latest technology.

Another factor studied during the study was about- frozen or fresh embryo. Currently, there are advances in cryopreservation, therefore, frozen embryo transfer (FET) is being done successfully, but there is confusion about the pregnancy outcome in frozen embryo transfer as it a recent advance and if it produces similar or better outcomes than fresh embryo transfer. It is found in multiple studies, the results were obtained similar for both frozen and fresh embryo transfer, but they used best quality embryos in the study. ${ }^{3}$ In this study, the objective is to see which conditions can achieve the maximum success rate for embryo transfer.

\section{METHODS}

A retrospective study was performed in the months of December 2018, January, February and March 2019. The study included 87 patients who had undergone embryo transfers during the duration of the study from an IVF centre in Ahmedabad, Gujarat, India.

\section{Inclusion criteria}

- Patients who underwent embryo transfer during the duration of the study and patients who gave consent to participate in the study.

\section{Exclusion criteria}

- Patients who did not given consent to participate in the study.

\section{There were three factors studied affecting pregnancy outcomes during the study}

- The number of embryos transferred.

- The day on which the embryo was transferred -day 3 or day 5 .

- If the embryo was frozen or fresh.

The factors were studied and the clinical outcome was tabulated. The pregnancy outcomes were compared using the values of beta- hcg (human chorionic gonadotropin). The beta-hcg levels measured 15 days after the process of embryo transfer and the levels of 100 or more was considered positive.

The data was compiled and analysed using Google spreadsheets. To find the statistical difference between different factors- the statistical method of Fischer's exact test and p-value was used. A null hypothesis was formed with no statistical difference taken into consideration and Fischer's exact test value and p-value was calculated to find the possible association between the decided factors. The confidence interval taken for $\mathrm{p}$-value is $95 \%$ with 0.05 level of significance. Values corresponding $<0.05$ are found significant, the null hypothesis stands void and the factors are found to be associated for $95 \%$ confidence level.

\section{RESULTS}

A total 87 patients participated in the study. Pregnancy outcomes of the patients were studied, out of the 87 patients, $45.97 \%$ patients had a positive outcome of pregnancy and $54 \%$ are negative (Table 1). Multiple factors affecting the pregnancy outcomes were studied. These factors include- The pregnancy outcomes of embryo transfer on day 3 versus the embryo transfers on day 5 , pregnancy outcomes of embryo due to the number of embryos transferred and pregnancy outcomes due to fresh versus frozen embryo transfer.

Table 1: Indicating pregnancy outcomes of the patients.

\begin{tabular}{|lll|}
\hline Variable & $\begin{array}{l}\text { Positive } \\
\text { pregnancy } \\
\text { outcome }\end{array}$ & $\begin{array}{l}\text { Negative } \\
\text { pregnancy } \\
\text { outcome }\end{array}$ \\
\hline $\begin{array}{l}\text { Number of } \\
\text { patients }\end{array}$ & 40 & 47 \\
\hline
\end{tabular}

Table 2: Indicating pregnancy outcomes with variation of the day of the embryo transfer.

\begin{tabular}{|llll|}
\hline Variable & $\begin{array}{l}\text { Positive } \\
\text { pregnancy } \\
\text { outcome }\end{array}$ & $\begin{array}{l}\text { Negative } \\
\text { pregnancy } \\
\text { outcome }\end{array}$ & $\begin{array}{l}\text { Percentage } \\
\text { of positive } \\
\text { outcome }\end{array}$ \\
\hline $\begin{array}{l}\text { Day 5 } \\
(n=59)\end{array}$ & 30 & 29 & $50.85 \%$ \\
\hline $\begin{array}{l}\text { Day 3 } \\
(n=28)\end{array}$ & 17 & 10 & $35.71 \%$ \\
\hline
\end{tabular}

Initially, day 3 versus day 5 transfer of embryo was studied. A null hypothesis of statistical difference between day 3 and day 5 was made. Fischer's exact test was performed. After statistical analysis, Fischer's exact test value found was - 0.3545. As p-value found was $>0.05$, the null hypothesis stands void and there is no statistical difference between day 3 and day 5 of embryo transfer for positive pregnancy outcome. Day 5 pregnancy rate found was $50.85 \%$ and day 3 pregnancy rate found was $35.71 \%$, although no statistical difference was found (Table 2).

The next factor studied was the number of embryos transferred affecting the pregnancy outcomes. 2- embryo transfers had the success rate of $44.1 \%$. 3 embryo transfers had the success rate of $57.57 \%, 5$ embryo transfer had similar result- $50.85 \%$. Transfers done with 1 embryo and 4 embryos failed and had low values. Thus, a 3 or a 5-embryo transfer has maximum positive outcomes (Table 3).

The next factor studied was the effect of quality of embryo transfer affecting the pregnancy outcome. Here, frozen versus fresh embryo transfer was studied. A null 
hypothesis of statistical difference between fresh and frozen embryo was made. Fischer's exact test was performed. After statistical analysis, Fischer's exact test found was -0.6674 . As, $p$-value found was $<0.05$, the null hypothesis stands void and there is no statistical difference between frozen and fresh embryo transfer for positive pregnancy outcome. Fresh embryo transfer pregnancy rate found was $45.76 \%$ and frozen embryo transfer pregnancy rate found was $46.42 \%$, although no statistical difference was found (Table 4).

Table 3: Number of embryo transfers affecting pregnancy outcomes.

\begin{tabular}{|c|c|c|c|}
\hline Variable & $\begin{array}{l}\text { Positive pregnancy } \\
\text { outcome }\end{array}$ & $\begin{array}{l}\text { Negative pregnancy } \\
\text { outcome }\end{array}$ & $\begin{array}{l}\text { Percentage of positive } \\
\text { outcome }\end{array}$ \\
\hline 1 embryo transfer $(n=4)$ & 0 & 4 & $0 \%$ \\
\hline 2 embryo transfer $(n=43)$ & 19 & 24 & $44.186 \%$ \\
\hline 3 embryo transfer $(n=33)$ & 19 & 14 & $57.57 \%$ \\
\hline 4 embryo transfer $(n=7)$ & 1 & 6 & $14.28 \%$ \\
\hline 5 embryo transfer $(n=59)$ & 30 & 29 & $50.85 \%$ \\
\hline
\end{tabular}

Table 4: Frozen versus fresh embryo transfer affecting pregnancy rate.

\begin{tabular}{|llll|}
\hline Variable & $\begin{array}{l}\text { Positive pregnancy } \\
\text { outcome }\end{array}$ & $\begin{array}{l}\text { Negative pregnancy } \\
\text { outcome }\end{array}$ & $\begin{array}{l}\text { Percentage of positive } \\
\text { outcome }\end{array}$ \\
\hline Frozen embryo transfer $(\mathrm{n}=28)$ & 13 & 15 & $46.42 \%$ \\
\hline Fresh embryo transfer $(\mathrm{n}=59)$ & 27 & 32 & $45.76 \%$ \\
\hline
\end{tabular}

\section{DISCUSSION}

In this study, although no statistical difference was found but authors found that day 5 transfer of embryo had more percentage of pregnancy outcomes than day 3 . There was another study that reported no statistical difference- A prospective randomized study reported that day 3 and day 5 transfers yielded statistically similar overall implantation (21\% versus $23 \%)$, pregnancy (39\% versus $39 \%)$ and twinning $(11.9 \%$ versus $15 \%)$ rates in a cohort of 201 infertile women. ${ }^{4}$ While there was a study in which the transfer of two blastocysts at day 5 was more favorable than two embryos at day $3 .^{5}$ In that study, transfers at blastocyst stage resulted in significantly higher pregnancy $(51.3 \%$ versus $27.4 \%$ ) and live birth $(47.5 \%$ versus $27.4 \%)$ rates than the transfers at the cleavage stage. 5 Yet, the twinning rate was statistically similar for the day 3 and day 5 transfers $(36.8 \%$ vs. $30.4 \%) .{ }^{4}$ This study did not detect statistically significant differences in pregnancy outcome of day 3 and day 5 transfers. This could be due to various factors- small sample size and relative heterogeneity in study population. The study population had various different clinical characteristics as age, cause of infertility, duration of infertility which could have also caused it, but according to the results of this study, authors recommend day 5 embryo transfer if facilities to preserve the embryo till day 5 are available and the quality of the embryo remains at it's best till the day of transfer. Authors have found that efficacy of blastocyst stage embryo transfer is not inferior to cleavage stage embryo transfer. This is also supported by a study which concluded that the maintenance of embryo culture until day 5 may be a more sensible approach for the correct identification of best quality embryos with the highest probability of success for implantation. ${ }^{6}$

Another factor studied was the efficacy of frozen versus fresh embryo transfer in the pregnancy outcome. In our study, authors did not find any difference in fresh versus frozen embryo transfer in the pregnancy outcome rate. Frozen embryo transfer can be performed successfully as we have advance techniques to preserve the frozen embryos without altering the quality of them. In recent studies, it was found that with the advances of the embryo cryopreservation techniques, the quality of the frozen embryos and their potential of implantation are similar to the observed with fresh embryos. ${ }^{7}$ Although in most of the studies comparing fresh and FET, the bestquality embryos are chosen for the fresh transfer, and the results are similar between the two types of treatments. ${ }^{8}$ Some studies have shown good results with the cryopreservation of all embryos and subsequent FET in patients with an increased risk ovarian hyperstimulation syndrome (OHSS). ${ }^{9-11}$ Therefore, it is more important to use the best quality embryos for frozen embryo transfer as well as fresh embryo transfer to obtain higher pregnancy outcomes.

Another factor studied was the number of embryo transfers affecting the pregnancy outcomes. In this study, we found maximum pregnancy outcomes with 3 and 5 embryo transfers. Although, it has also been observed that multiple pregnancies are a common complication of an in vitro fertilization process, the efficacy of pregnancy outcome is found more with 3 and 5 embryo transfer. 


\section{CONCLUSION}

In conclusion authors recommend a day 5 embryo transfer with 3 or 5 embryos which are best-quality frozen or fresh embryos to achieve maximum pregnancy outcomes.

\section{ACKNOWLEDGMENTS}

Authors would like to thank Shashwat IVF to give permission as well as guide through the study. Authors would also like to thank the participants of the study to provide their consent to perform the study.

Funding: No funding sources

Conflict of interest: None declared

Ethical approval: Not required

\section{REFERENCES}

1. Achache H, Revel A. Endometrial receptivity markers, the journey to success- ful embryo implantation. Hum Reprod Update. 2006;12:731-46.

2. Fleming R, Faye S. In vitro fertilization and embryo transfer (IVF-ET). The Immunoassay Handbook; 2013:735-743

3. Shapiro BS, Daneshmand ST, Garner FC, Aguirre M, Hudson C, Thomas S. Evidence of impaired endometrial receptivity after ovarian stimulation for in vitro fertilization: a prospective randomized trial comparing fresh and frozen-thawed embryo transfer in normal responders. Fertil Steril. 2011;96:344-8.

4. Coskun S, Hollanders J, Al-Hassan S, Al-Sufyan H, Al-Mayman H, Jaroudi K. Day 5 versus day 3 embryo transfer: a controlled randomized trial. Hum Reprod. 2000;15(9):1947-52.

5. Papanikolaou EG, Camus M, Kolibianakis EM, Van Landuyt L, Van Steirteghem A, Devroey P. In vitro fertilization with single blastocyst-stage versus single cleavage-stage embryos. N Engl J Med. 2006;354(11):1139-46.
6. Hatırnaz Ş, Pektaş MK. Day 3 embryo transfer versus day 5 blastocyst transfers: A prospective randomized controlled trial. Turkish $\mathbf{J}$ Obstet Gynecol. 2017;14(2):82.

7. Herrero L, Martínez M, Garcia-Velasco JA. Current status of human oocyte and embryo cryopreservation. Curr Opin Obstet Gynecol. 2011;23:245-50.

8. Shapiro BS, Daneshmand ST, Garner FC, Aguirre M, Hudson C, Thomas S. Evidence of impaired endometrial receptivity after ovarian stimulation for in vitro fertilization: a prospective randomized trial comparing fresh and frozen-thawed embryo transfer in normal responders. Fertil Steril. 2011;96:344-8.

9. Griesinger $\mathrm{G}$, von Otte S, Schroer A, Ludwig AK, Diedrich K, Al-Hasani S, et al. Elective cryopreservation of all pronuclear oocytes after GnRH agonist triggering of final oocyte maturation in patients at risk of developing OHSS: a prospective, observational proof-of-concept study. Hum Reprod. 2007;22:1348-52.

10. d'Angelo A. Ovarian hyperstimulation syndrome prevention strategies: cryo- preservation of all embryos. Semin Reprod Med. 2010;28:513-8.

11. Griesinger G, Schultz L, Bauer T, Broessner A, Frambach T, Kissler S. Ovarian hyperstimulation syndrome prevention by gonadotropin-releasing hormone agonist triggering of final oocyte maturation in a gonadotropin-releasing hormone antagonist protocol in combination with "freeze-all", strategy: a prospective multicentric study. Fertil Steril. 2011;95:2029-33.

Cite this article as: Singh PT, Singhvi SD, Kachhia U, Punjabi T, Punjabi S, Punjabi R. Retrospective study of multiple factors imparting effect on pregnancy outcomes in an in-vitro-fertilization centre. Int J Reprod Contracept Obstet Gynecol 2020;9:2516-9. 